\title{
Alterações esofágicas em modelo de esclerodermia induzido por colágeno V em coelhos
}

\author{
Manifestations in the esophagus in the \\ scleroderma model induced by type \\ $V$ collagen in rabbits
}

\author{
Guilherme Pagin São Julião', Diego Daniel Pereira', \\ Daniel Marchi dos Anjos', Walcy Rosolia Teodoro', \\ Natalino Hajime Yoshinari ${ }^{2}$, Ana Paula Pereira Velosa ${ }^{2}$
}

Julião GPS, Pereira DD, Anjos DM dos, Teodoro WR, Yoshinari NH, Velosa APP. Alterações esofágicas em modelo de esclerodermia induzido por colágeno $V$ em coelhos. Rev Med (São Paulo). 2007 jul.-set.;86(3):163-73.

\begin{abstract}
RESUMO: Introdução: a esclerose sistêmica progressiva acomete diversas vísceras, das quais o esôfago é uma das mais freqüentemente lesadas. No entanto, o mecanismo de autoimunidade nesta enfermidade é ainda desconhecido. Objetivo: avaliar morfologicamente esôfagos de animais após imunização com colágeno tipo V, correlacionando-os com as alterações observadas em humanos. Materiais e métodos: foram analisados esôfagos de coelhos do modelo de esclerodermia induzido por colágeno $\mathrm{V}$. As amostras foram analisadas morfologicamente pelas técnicas de H\&E, Tricrômico de Masson, Picro Sirius e Imunofluorescência. Resultados: observou-se aumento progressivo das fibras colágenas, caracterizado por alterações no epitélio, submucosa, camada muscular e adventícia. A análise da imunofluorescência revelou a existência de remodelamento dos diferentes tipos de colágeno da matriz. Discussão: o estudo de espécimes esofágicos em humanos é difícil. Na maioria das vezes só é possível analisá-lo em fases avançadas da doença. No modelo estudado acreditamos que as alterações observadas estão relacionadas a um processo inicial da doença e que o estudo de animais sacrificados após um tempo maior irá revelar uma fase mais avançada da doença.
\end{abstract}

DESCRITORES: Esclerodermia localizada. Esofagopatias. Modelos animais. Coelhos. Colágeno tipo V. Avanço da doença.

POC - Área Básica

1. Alunos acadêmicos.

2. Orientadores.

Endereço para correspondência: Guilherme Pagin São Julião. Rua Teodoro Sampaio, 632 apt 101. Pinheiros CEP: 05406-000 São Paulo - SP. e-mail: guilhermepc91@yahoo.com.br 
Julião GPS et al. Alterações esofágicas em modelo de esclerodermia induzido por colágeno.

\section{INTRODUÇÃO}

$\mathrm{M}$ uitas doenças reumáticas autoimunes têm sido amplamente estudadas, incluindo aspectos de sua patogênese, eventos que possam alterar a regulação da resposta imune e manifestação da doença. Entre essas doenças, a esclerodermia se caracteriza por aumento do tecido conjuntivo fibroso da pele e freqüentemente de órgãos viscerais, variando em extensão e gravidade de segmento de pele endurecida a uma condição generalizada ${ }^{24}$. No entanto, o mecanismo de autoimunidade nesta enfermidade é ainda desconhecido. Diversos fatores podem contribuir para a manifestação da doença e aumento de sintomas, sendo estudos em animais de grande auxílio no esclarecimento do processo da doença.

Nas doenças reumáticas autoimunes um dos aspectos mais freqüentes são as alterações esofágicas, chegando a $90 \%$ nos pacientes com esclerodermia ${ }^{2-4}$.

Nesta doença o acometimento esofágico destaca-se principalmente pela fibrose da lâmina própria, submucosa e camada muscular do esôfago, presença de áreas com células inflamatórias, causando diminuição do peristaltismo e atrofia da musculatura. A porção distal e o esfíncter inferior (EEI) são os mais acometidos e podem apresentar erosões e ulcerações pépticas na mucosa decorrentes do refluxo gastroesofágico ${ }^{11}$. Clinicamente, os sintomas mais referidos pelos pacientes com acometimento gastrointestinal são disfagia, pirose, náusea, vômito, diarréia, constipação intestinal e incontinência fecal ${ }^{30}$. Apesar de tão prevalentes, pouco se conhece sobre a patogênese das lesões do trato digestivo na esclerodermia, assim como nas demais doenças difusas do tecido conjuntivo (DDTC).

Entre os vários tipos de colágeno, o tipo $\mathrm{V}$ parece estar envolvido na patogênese destas doenças. Pertencente à subclasse dos colágenos fibrilares que apresenta um domínio em tríplice hélice composto pela seqüência Gly-X-Y que apresenta características próprias. Durante a sua síntese ele conserva os domínios globulares e telopeptídeos $\left(\mathrm{NH}_{3}\right.$ e $\left.\mathrm{COOH}\right)$, regiões reconhecidamente imunogênicas da molécula ${ }^{15}$. Apesar deste tipo de colágeno corresponder de 5 a $15 \%$ nos tecidos intersticiais humanos, desempenha papel fundamental nos processos de proliferação, adesão e reparação celular, além de interagir com os diferentes componentes da matriz extracelular. O colágeno do tipo $\mathrm{V}$ está distribuído principalmente na córnea, fígado, baço, pulmão, pele e na membrana basal de vasos e em tecidos mesenquimatosos, promovendo a ligação entre o colágeno IV da membrana basal e o conjuntivo frouxo dos órgãos ${ }^{1}$.

As alterações esofágicas são pouco encontra- das nos modelos de DDTC, sendo apenas descritas em alguns modelos de esclerose sistêmica. Estudos anteriores realizados por Gershwin, em 1981, descreveram que galinhas da linhagem UCD 200 desenvolviam lesão endotelial espontânea, seguida de fibrose e infiltração mononuclear no esôfago em estágios iniciais da doença ${ }^{20}$.

Teodoro, em sua tese de doutorado, em 2001, descreveu alterações pulmonares semelhantes ao padrão histológico das DDTC, em coelhos sensibilizados com colágeno tipo $\mathrm{V}$ humano, além da presença de anticorpos contra colágeno dos tipos I e III26, 27 .

Posteriormente, Yoshinari et al. ${ }^{32}$, em 2002, observaram que após a sensibilização com colágeno V, múltiplos órgãos apresentavam fibrose, como pele, coração, rim e sinóvia. O acometimento esofágico também foi demonstrado pelos autores através da diminuição do lúmen e nítida deposição da proteína colágena nas camadas submucosa e muscular, sugerindo similaridade dessas alterações teciduais com as encontradas na esclerodermia sistêmica.

Sabendo que dentre os aspectos clínicos gastrointestinais na esclerodermia o acometimento esofágico é o mais prevalente e que estas alterações podem estar relacionadas com componentes da matriz extracelular, temos como objetivo avaliar a disposição e a variedade de tipos de colágeno neste tecido após a sensibilização com colágeno $\mathrm{V}$, tentando relacionar alterações do colágeno no modelo com as encontradas no tecido esofágico humano de pacientes com esclerodermia.

\section{MATERIAIS E MÉTODOS}

\section{Protocolo experimental}

\section{Antígeno}

Foi utilizado como imunógeno em nossos experimentos, colágeno do tipo $\mathrm{V}$, isolado de placenta humana, provenientes do Serviço de Ginecologia e Obstetrícia do HC-FMUSP, isolado de acordo com método de Niyibizi et al. ${ }^{21}$. A pureza do antígeno foi testada por Immunoblot contra anticorpos anticolágeno dos tipos I, III e V'28.

\section{Protocolo de imunização}

Foram utilizados coelhos da linhagem Nova Zelândia, fêmeas ( $n=39$ ) com peso médio de $2.500 \mathrm{~g}$ e 2 meses de idade, divididas em quatro grupos: controle e imunizado, de 75 e 120 dias. Os animais foram inoculados via subcutânea com $1 \mathrm{ml}$ de uma solução de $1 \mathrm{mg} / \mathrm{ml}$ de colágeno do tipo $V$ em ácido acético $10 \mathrm{mM}$, emulsificado com igual volume de adjuvante completo 
de Freund. Após 4 semanas foi administrada a mesma dose de antígeno. A seguir com intervalos de 15 dias os animais receberam adicionalmente dois reforços via intramuscular de $1 \mathrm{mg} / \mathrm{ml}$ de colágeno tipo V em ácido acético $10 \mathrm{mM}$ emulsificado com $1 \mathrm{ml}$ de adjuvante incompleto de Freund. Após 75 e 120 dias da primeira imunização o esôfago foi isolado e seccionado em dois fragmentos: proximal e distal, e fixados em formol $10 \%$. Cada grupo de estudo foi comparado com o grupo controle inoculado com $1 \mathrm{ml}$ da solução de ácido acético $10 \mathrm{mM}$ emulsificado com igual volume de adjuvante de Freund, tendo sido feita a coleta nos mesmos períodos ${ }^{26}$.

\section{Estudo histológico}

\section{Preparo das lâminas}

Cortes com 2 a 3 micrômetros de espessura foram corados com H\&E, tricrômico de Masson e Picro Sirius, com a finalidade de analisar o processo inflamatório e o colágeno tecidual em microscópio óptico e luz polarizada.

\section{Critério histológico}

Baseado no comprometimento esofágico da esclerodermia, o esôfago foi avaliado quanto a: 1 - Tipo de tecido conjuntivo (normal e remodelado); 2 - Componentes inflamatórios (fibrina, polimorfonucleares e células mononucleares); 3 - Vasos (normal e remodelado); e 4 - Extensão e distribuição do processo patológico.

Quantificação dos cortes histológicos por análise de imagem

Para análise das lâminas coradas pelo Sirius red foi utilizado um analisador de imagem acoplado a um microscópio óptico equipado com um polarizador de luz. O sistema utilizado consiste de uma câmera CCD Sony acoplada a um microscópio Leica, a partir do qual as imagens podem ser visualizadas no monitor. Através de um sistema digital inserido num computador (Pentium III 300Mhz), as imagens foram processadas por um "software" Image ProPlus. Para que houvesse a visualização de todo o esôfago em apenas um campo, foi utilizada uma lente objetiva de aumento $1 \mathrm{x}$, adaptada ao microscópio.

Foi realizada a medida da área do esôfago através da delimitação manual, com o auxílio do "mouse". As áreas obtidas eram em $\mu^{2}$. Com o objetivo de minimizar o erro, foram realizadas três medidas da mesma área de cada lâmina e obtido a média. As áreas analisadas foram: Área do Lúmen $(A L)$, delimitada a partir da borda luminal do epitélio esofágico; Área Total (AT), delimitada a partir da borda externa da camada muscular do esôfago e Área Média (AMe), delimitada pela borda interna da camada muscular do esôfago. A Área Muscular $(\mathrm{AMu})$, correspondente à camada muscular, pode ser obtida pela seguinte fórmula:

$$
\mathrm{AT}-\mathrm{AMe}=\mathrm{AMu}
$$

Para a determinação dos valores do espessamento foi considerado que as áreas correspondem a círculos. Sendo assim, calculou-se o Raio (R1) referente à Área Total (AT) e o Raio (R2) referente à Área do Lúmen (AL), através da seguinte fórmula: $A=\partial R^{2}$. Foi considerado espessamento esofágico médio (EE) a diferença entre R1 e R2 ( $E E=R 1-R 2)$. $O$ valor do espessamento muscular médio (EM), foi determinado pela diferença entre R1 e R3, onde R3 é o raio referente à Área Média $(\mathrm{AMe})(\mathrm{EM}=\mathrm{R} 1$ R3) (Figura 1).

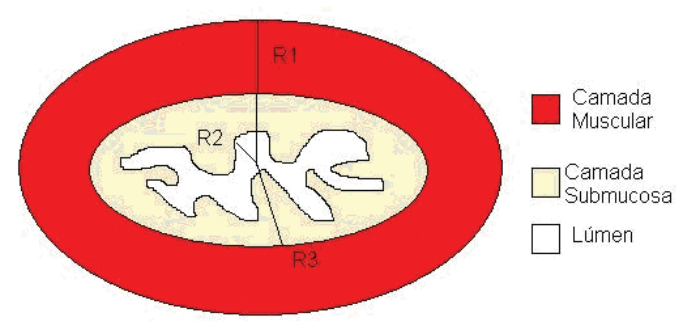

Figura 1. Esôfago esquemático apresentando os raios utilizados.

\section{Imunofluorescência}

Cortes transversais de esôfago de coelhos preparados em lâminas previamente tratadas com 3-aminopropiltriethoxy Silano (Sigma), foram imersos em xilol quente por 20 minutos, a seguir submetidos á dois banhos de xilol frio e hidratados com sucessivas lavagens com álcool etílico, em concentrações decrescentes (100\%-75\%), água destilada e tampão fosfato de sódio (PBS). Para a exposição e recuperação de sítios antigênicos, o material foi digerido com pepsina de porco (10000U/ ml) (SIGMA Co) por 30 minutos a $37^{\circ} \mathrm{C}$, dissolvida em ácido acético a $0,5 \mathrm{M}$. Os cortes tratados foram lavados por três vezes, 10 minutos cada, com PBS e a reação foi bloqueada com leite Molico a 5\% em PBS durante 30 minutos. As lâminas foram incubadas durante uma noite com os anticorpos policlonais anticolágeno do tipo $\mathrm{V}$ humano (1:50) e anticolágeno I (1:50) produzidos em camundongos e anticolágeno do tipo III monoclonal (Oncogene) (1:50). Após este período, os cortes foram lavados em PBS, com Tween ${ }_{20} 0.05 \%$ e incubados por 1 hora com anticorpo secundário anti-lgG de camundongo conjugado com fluoresceína (Dako) diluído 1: 50 em solução de PBS contendo azul de Evans $0.005 \%$ e montadas com solução de glicerina 
tamponada. A reação foi analisada em microscópio de fluorescência marca Nikon ${ }^{26}$.

\section{Estatística}

As amostragens obtidas da análise quantitativa dos animais imunizados e controles foram expressas como média \pm desvio padrão. A análise descritiva foi demonstrada pelo teste ANOVA, que foi aplicado para se verificar as diferenças das médias obtidas entre os grupos. Também o teste de Turkey aplicado e o t test foram utilizados para identificar as diferenças entre as médias. O nível de significância estabelecido foi de $p<0,05$.

\section{RESULTADOS}

Foram incluídos retrospectivamente 39 coelhos
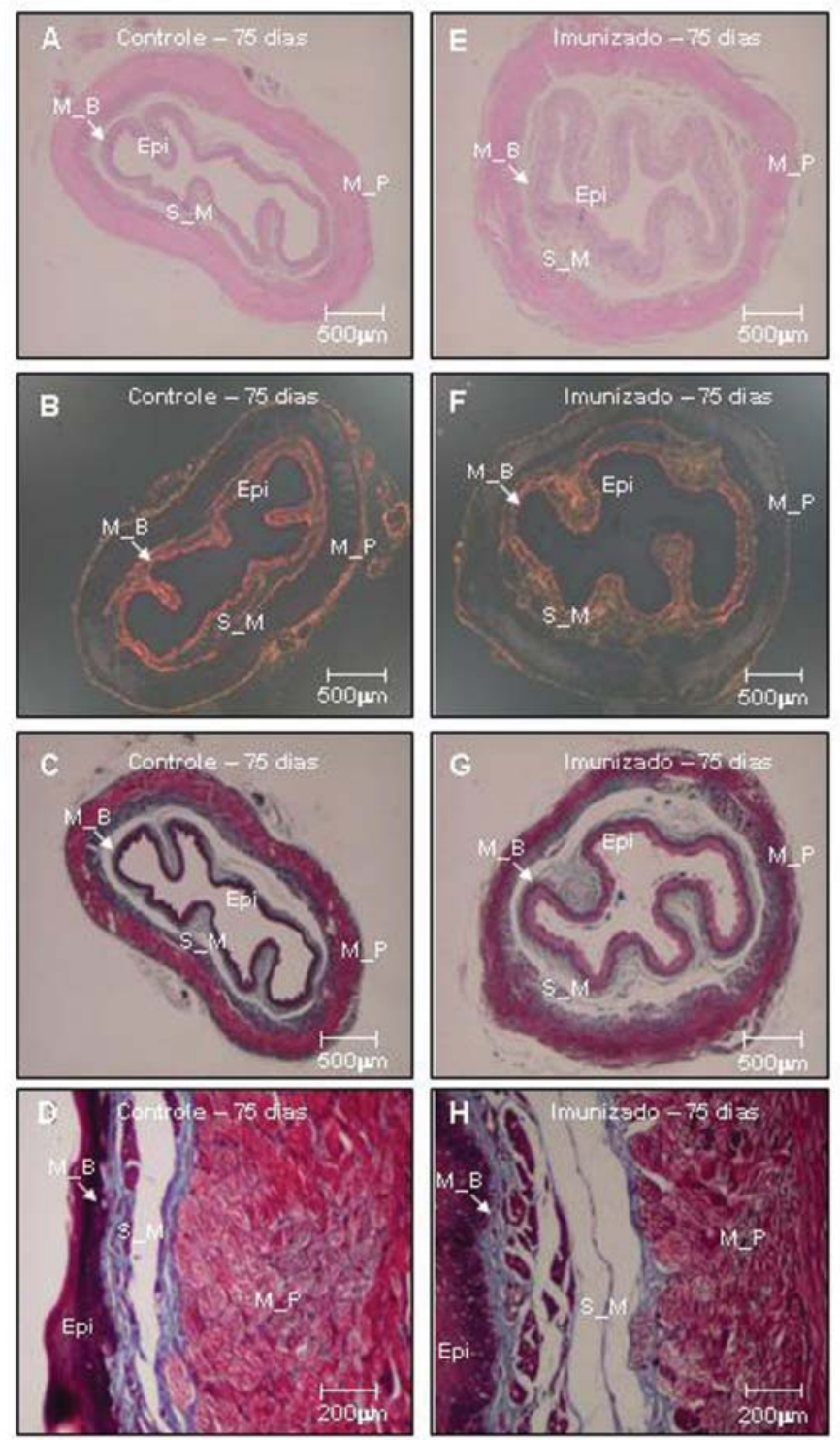

submetidos ao protocolo de imunização com colágeno $\mathrm{V}$, estando divididos em 4 grupos assim distribuídos: 10 coelhos no grupo controle sacrificados com 75 dias (C-75), 11 coelhos no grupo imunizado de 75 dias (I-75), 8 coelhos no grupo controle de 120 dias (C-120) e 10 coelhos no grupo imunizado de 120 dias (I-120).

Os esôfagos dos coelhos foram comparados quanto às alterações morfológicas entre os grupos controle e imunizado e sua progressão no intervalo de 75 para 120 dias. Pela coloração com H\&E, Tricrômico de Masson e Picro Sírius verificou-se um espessamento e retificação do epitélio e aumento de fibras colágenas na submucosa (cório) no grupo I-75 em relação ao grupo C-75. Observou-se também uma alteração da camada muscular da mucosa e presença de traves fibrosas dissociando os feixes de fibras musculares, assim como um discreto espessamento da adventícia (Figura 2). Todo este processo se mostrou mais intenso quando analisado o grupo $\mathrm{I}-120 \mathrm{em}$ comparação ao grupo C-120 (Figura 3).

Figura 2. (Painéis A-D: cortes histológicos de esôfago de animais controle de 75 dias; Painéis E-H cortes de esôfago de animais imunizados com colágeno $\mathrm{V}$ de 75 dias) Em E observa-se retificação do epitélio, dissociação dos feixes musculares e discreto espessamento da camada adventícia, comparado com seu respectivo controle em $\mathrm{A}$. Em $\mathrm{F} \mathrm{e} \mathrm{G}$ depósito de colágeno na região submucosa (cório) assim como entre as fibras musculares demonstrados em $\mathrm{H}$ (Painéis A-C, E-G, aumento 10X; D,H, aumento 100X; Painéis $A$ e $E$ corados com H\&E, Painéis $B$ e $F$ corados com Picro-sírius visualizados sob luz polarizado, Painéis C, D, G e H corados com Tricrômico de Masson). Legenda: Epi: Epitélio; M_B: Membrana Basal; S_M: Sub-Mucosa; M_P: Muscular Própria 

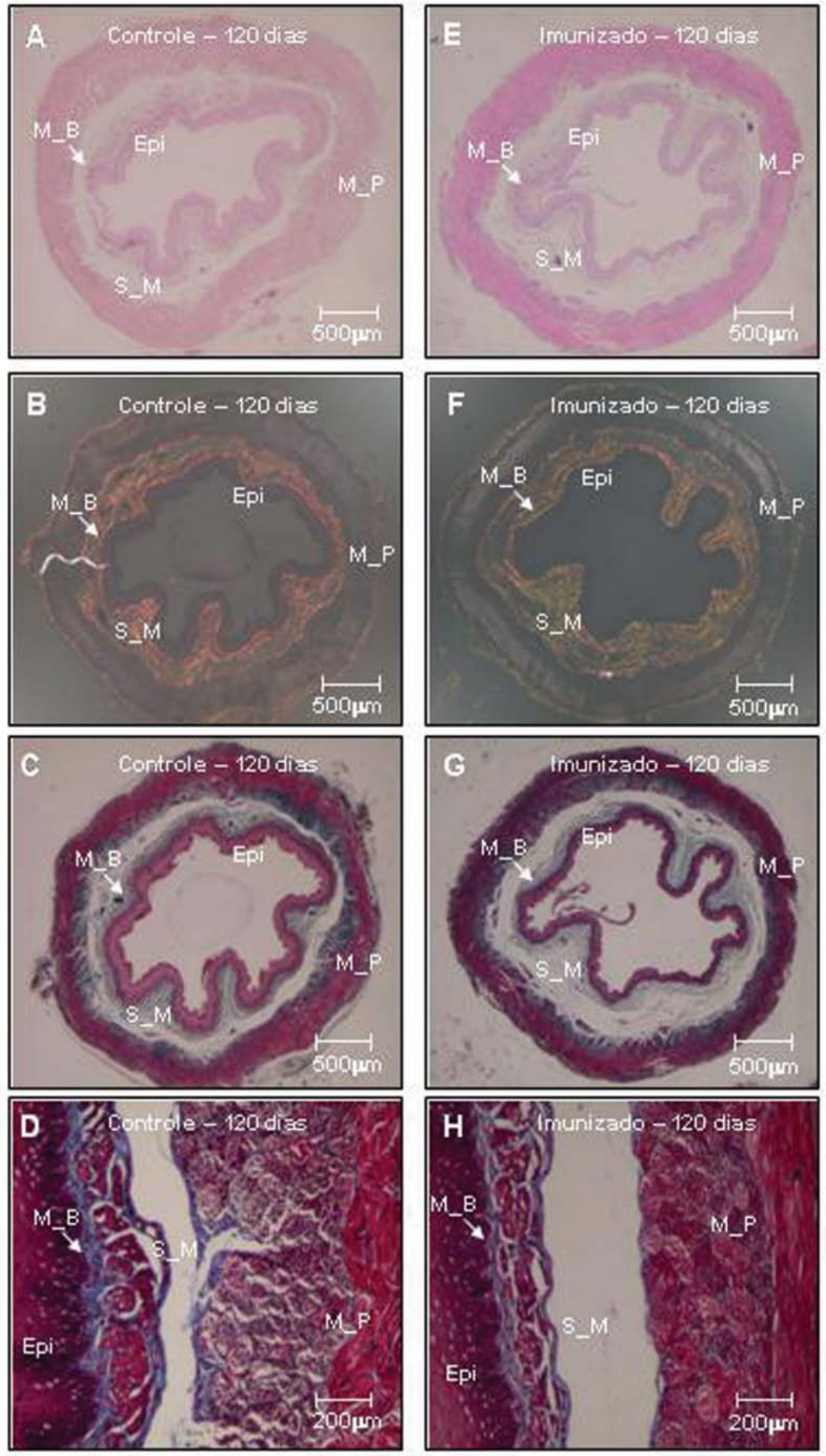

Figura 3. (Painéis A-D: cortes histológicos de esôfago de animais controle de 120 dias; Painéis E-H cortes de esôfago de animais imunizados com colágeno V de 120 dias) Em E observa-se aumento na retificação do epitélio, assim como nas alterações musculares, comparado com seu respectivo controle em A. Em F, G e H observa-se maior intensidade no depósito de colágeno na região submucosa (cório) e também entre as fibras musculares demonstrados em H (Painéis A-C, E-G, aumento 10X; D,H, aumento 100X; PainéiA e E corados com H\&E, painéis B e F corados com Picro-sírius visualizados sob luz polarizado, painéis $C, D, G$ e H corados com Tricrômico de Masson). Legenda: Epi: Epitélio; M_B: Membrana Basal; S_M: Sub-Mucosa; M_P: Muscular Própria 
Julião GPS et al. Alterações esofágicas em modelo de esclerodermia induzido por colágeno.

A avaliação morfológica e imunohistoquímica do colágeno I das amostras de esôfago de I-75 mostraram uma discreta diminuição deste colágeno predominante-mente na região da submucosa da parede esofágica, mantendo a distribuição delicada em volta dos feixes musculares, da mesma forma como foram observa-dos em C-75 (Figura 4, Painéis A e B).
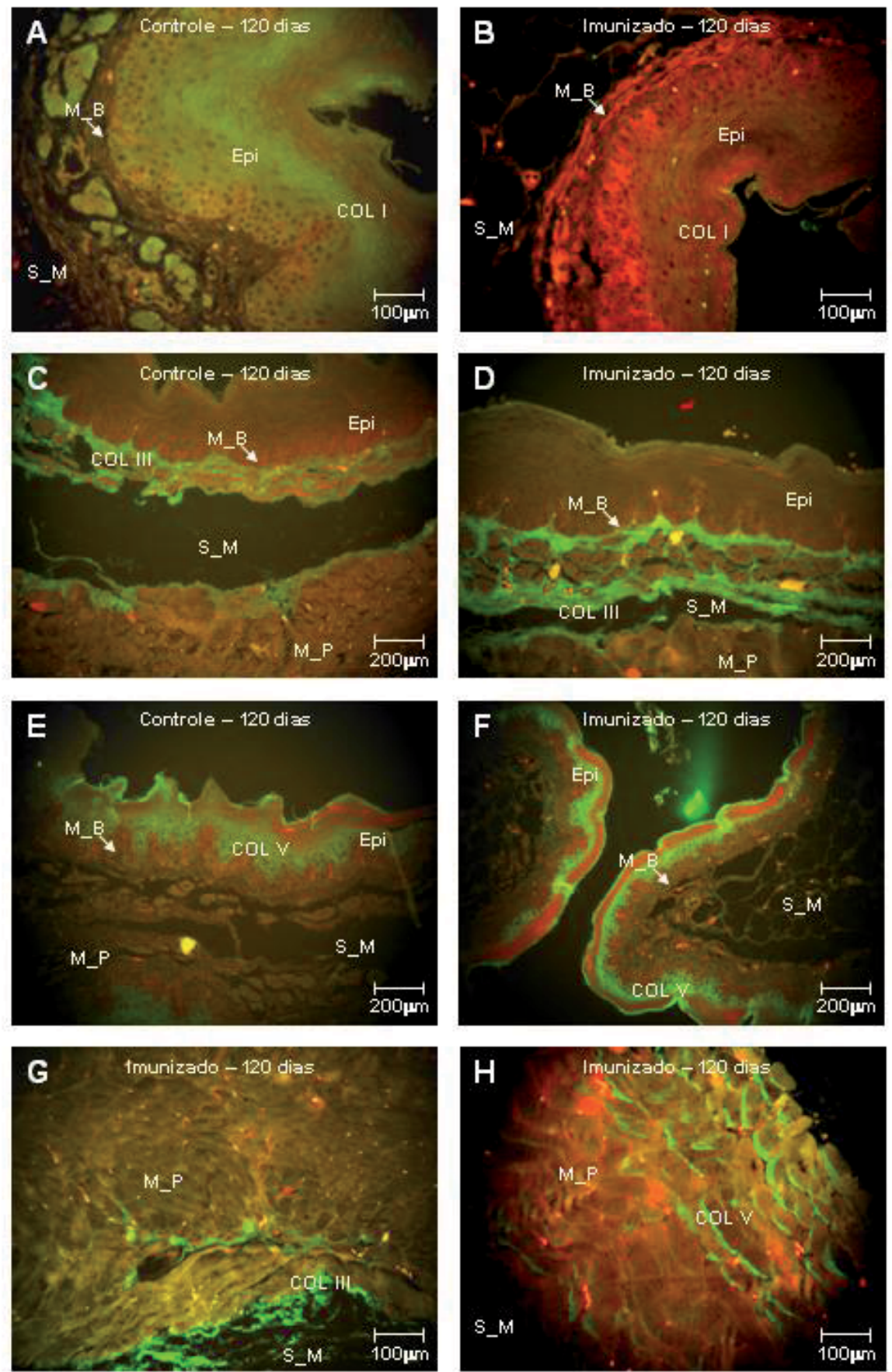

Epi: Epitélio; M_B: Membrana Basal; S_M: Sub-Mucosa; M_P: Muscular Própria.

Figura 4. Imunomarcação para colágeno dos tipos I, Ill e V em esôfago de animais imunizados com colágeno V, 75 dias após a primeira imunização. No painel $(B)$ o colágeno tipo I mostrou-se diminuído entre as células do epitélio esofágico e submucosa, quando comparado com o controle sensibilizado com adjuvante de Freund (A). Em (D), nota-se um aumento de colágeno tipo III na região da membrana basal, sub-mucosa e camada muscular, comparado com o seu respectivo controle (C). Em (F), observamos o colágeno do tipo V diminuído na submucosa, comparado com o controle em $(E)$. Em $(H)$, nota-se uma mudança de padrão deste tipo de colágeno no animal imunizado com espessamento de suas fibras, em relação ao seu controle em (G). (Painéis A-F, aumento 100X; $G$ e H, aumento 200X; imunofluorescência) 
Em l-120 o colágeno I mostrou uma diminuição mais acentuada nas áreas descritas anteriormente quando comparado ao grupo C-120 (Figura 5, Painéis $A$ e $B$ ).

O colágeno do tipo III nos primeiros 75 dias mostrou uma maior birrefringência na região submucosa, assim como ao nível da membrana basal do epitélio esofágico (Figura - 4, Painéis C e D). Aos 120 dias este colágeno apresentou aumento da birrefringência com predomínio das regiões da submucosa e ao redor dos feixes musculares da camada muscular em relação ao grupo controle sensibilizado com ad- juvante de Freud (Figura 5, Painéis C e D).

$\mathrm{A}$ avaliação do colágeno do tipo $\mathrm{V}$ mostrou aumento da birrefringência na região da membrana basal com um dramático aumento destas fibras em volta dos feixes musculares da camada muscular da parede esofágica. Este aumento da birrefringência do colágeno tipo $\mathrm{V}$ em volta dos feixes musculares foi ainda maior nos animais após 120 dias da primeira imunização. Estas diferenças são marcantes quando comparados aos grupos controles (Figura 5, Painéis E e F) (Figura 5, Painéis E e F).
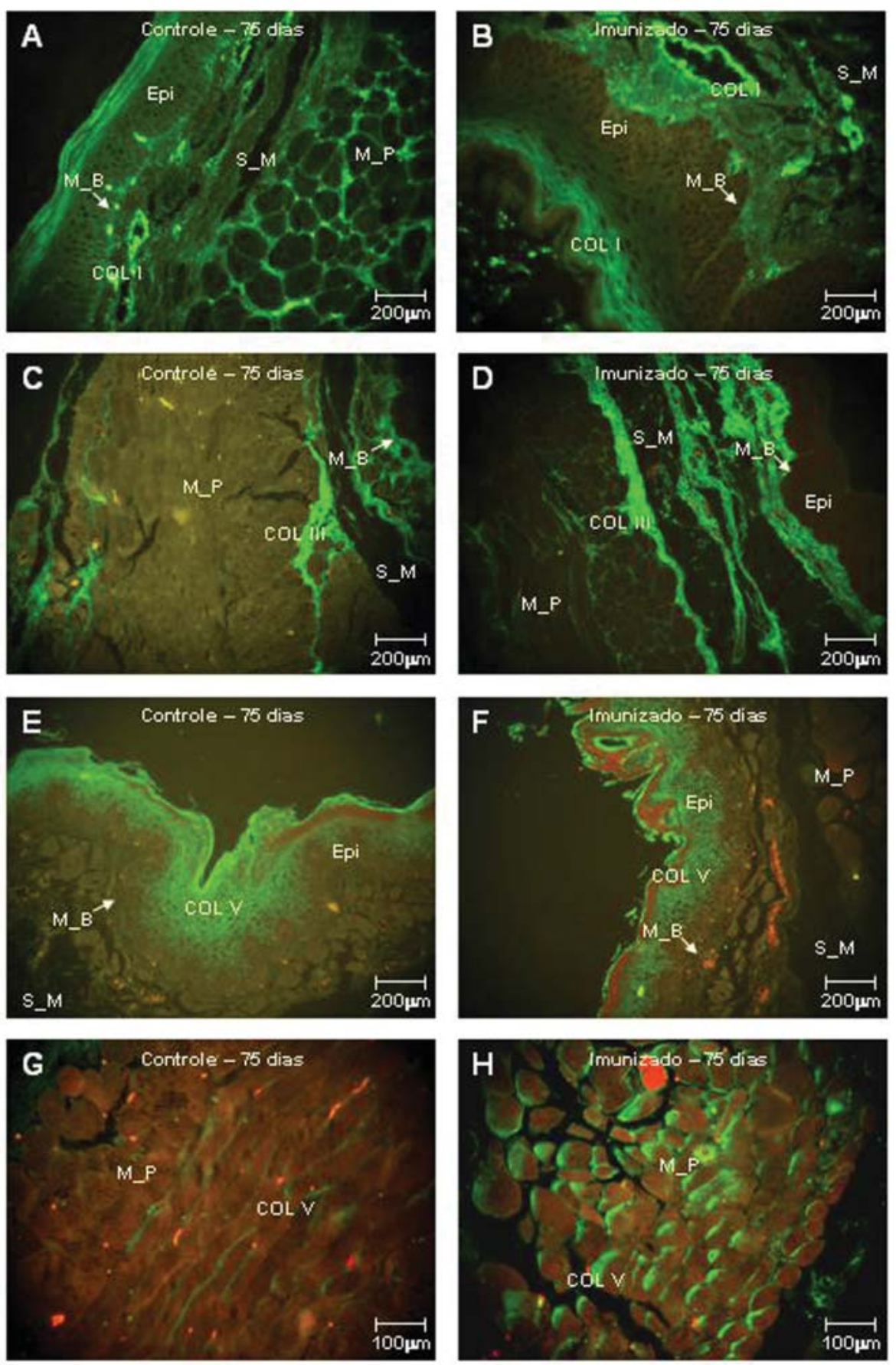

Figura 5. Imunomarcação para colágeno dos tipos I, III e V em esôfago de animais imunizados com colágeno $\mathrm{V}, 120$ dias após a primeira imunização. No painel (B) o colágeno tipo I mostrou intensificação do processo de diminuição do colágeno entre as células do epitélio esofágico e submucosa, quando comparado com o controle sensibilizado com adjuvante de Freund (A). Em (D), nota-se um aumento mais expressivo de colágeno tipo III na região da membrana basal, sub-mucosa e camada muscular, comparado com o seu respectivo controle (C). Em (F), observamos o colágeno do tipo V diminuído na submucosa, comparado com o controle em (E). Em (H), nota-se um aumento deste tipo de colágeno entre as fibras musculares no animal imunizado de 120 dias, em relação ao seu controle em (G). (Painéis A-F, aumento 100X; G e H, aumento 200X; imunofluorescência). Legenda: Epi: Epitélio; M_B: Membrana Basal; S_M: Sub-Mucosa; M_P: Muscular Própria 
Julião GPS et al. Alterações esofágicas em modelo de esclerodermia induzido por colágeno.

A análise quantitativa da área do lúmen e camadas musculares e espessamento eso-fágico e das camadas musculares dos animais imunizados não apresentou diferença esta-tística comparados com os grupos controles (Tabela 1).

Tabela 1. Análise comparativa da extensão das alterações morfológicas (área do lúmen, área da camada muscular, espessamento esofágico e espessamento da camada muscular) encontradas nos diferentes grupos de animais imunizados e seus respectivos controles

\begin{tabular}{|c|c|c|c|c|c|}
\hline Alterações Morfológicas & Amo & ras & $\mathrm{N}$ & Média \pm SD & $p$ \\
\hline Área do lúmen $\left(\mu \mathrm{m}^{2}\right)$ & $\begin{array}{l}75 \text { dias } \\
120 \text { dias }\end{array}$ & $\begin{array}{l}\text { Controle } \\
\text { limunizado } \\
\text { Controle } \\
\text { imunizado }\end{array}$ & $\begin{array}{l}10 \\
11 \\
8 \\
10\end{array}$ & $\begin{array}{l}3260405,96 \pm 639203,97 \\
2085852,36 \pm 695968,77 \\
2059869,11 \pm 639203,97 \\
2252631,88 \pm 1078558,81\end{array}$ & $\begin{array}{l}0,096 \\
0,662\end{array}$ \\
\hline $\begin{array}{l}\text { Área da camada muscular } \\
\left(\mu m^{2}\right)\end{array}$ & $\begin{array}{l}75 \text { dias } \\
120 \text { dias }\end{array}$ & $\begin{array}{l}\text { Controle } \\
\text { imunizado } \\
\text { Controle } \\
\text { imunizado }\end{array}$ & $\begin{array}{l}10 \\
11 \\
8 \\
10\end{array}$ & $\begin{array}{l}7171763,81 \pm 1639549,42 \\
7401365,98 \pm 1817327,92 \\
7158897,25 \pm 892837,67 \\
7344946,15 \pm 1359844,59\end{array}$ & $\begin{array}{l}0,765 \\
0,744\end{array}$ \\
\hline $\begin{array}{l}\text { Espessamento esofágico } \\
(\mu \mathrm{m})\end{array}$ & $\begin{array}{l}75 \text { dias } \\
120 \text { dias }\end{array}$ & $\begin{array}{l}\text { Controle } \\
\text { imunizado } \\
\text { Controle } \\
\text { imunizado }\end{array}$ & $\begin{array}{l}10 \\
11 \\
8 \\
10\end{array}$ & $\begin{array}{l}1159,65 \pm 280,91 \\
1318,23 \pm 263,78 \\
1314,34 \pm 136,88 \\
1334,03 \pm 177,04\end{array}$ & $\begin{array}{l}0,198 \\
0,799\end{array}$ \\
\hline $\begin{array}{l}\text { Espessamento da camada } \\
\text { muscular }(\mu \mathrm{m})\end{array}$ & $\begin{array}{l}75 \text { dias } \\
120 \text { dias }\end{array}$ & $\begin{array}{l}\text { Controle } \\
\text { imunizado } \\
\text { Controle } \\
\text { imunizado }\end{array}$ & $\begin{array}{l}10 \\
11 \\
8 \\
10\end{array}$ & $\begin{array}{l}628,16 \pm 132,68 \\
649,00 \pm 123,78 \\
634,53 \pm 76,12 \\
631,61 \pm 86,12\end{array}$ & $\begin{array}{l}0,714 \\
0,941\end{array}$ \\
\hline
\end{tabular}

\section{DISCUSSÃO}

O processo fisiopatológico nas DDTC está relacionado a um processo de autoimunidade, contudo ainda não está bem esclarecido. Este processo se caracteriza pela presença de autoanticorpos dirigidos a diferentes constituintes próprios, sendo que o remodelamento da matriz extracelular em diferentes órgãos é responsável pelos quadros clínicos.

Autoimunidade aos colágenos é freqüentemente observada nas DDTC. Modelos de sensibilização com os colágenos tipo II, IX e XI mostraram que estas proteínas possuem funções imunogênicas e artritogênicas ${ }^{5,10,12}$. A importância dos anticorpos anticolágeno nas DDTC já foi observada, principalmente a freqüência de anticolágenos I, II, IV e V em pacientes com vasculites e lúpus eritematoso sistêmico ${ }^{19}$; anticolágenos I e IV na esclerose sistêmica ${ }^{16}$; e anticorpos anticolágeno VII na Síndrome de Sjörgren ${ }^{6}$.

Dentre os diversos colágenos, o do tipo $\mathrm{V}$ parece estar envolvido na patogênese das DDTC. Ele corresponde de 5 a $15 \%$ nos tecidos intersticiais humanos, desempenhando papel fundamental nos processos de proliferação, adesão e reparação celular, além de interagir com os diferentes componentes da matriz extracelular. Sabe-se que este colágeno conserva os domínios globulares e telopeptídeos $\left(\mathrm{NH}_{3} \mathrm{e}\right.$ $\mathrm{COOH}$ ) durante sua síntese e que estas regiões são imunogênicas ${ }^{15}$. Mares et al. ${ }^{17}$ em 2000, trabalhando com modelo de rejeição a transplante em pulmão de murinos, mostraram que o colágeno tipo $\mathrm{V}$ é alvo da resposta imune para aloantígenos. Foi observado pelos autores que o sítio de lesão patológica em resposta a aloantígenos parece ocorrer, principalmente, nos tecidos em que o colágeno V está localizado, como: o tecido conjuntivo peribronquiolar, interstício alveolar e membrana basal dos capilares. Além destes achados, Haque et al. ${ }^{8} 2002$, encontraram células T específicas 
para o colágeno $\mathrm{V}$ durante os episódios de rejeição do enxerto de pulmão e verificaram que estas células podem contribuir para patogênese das respostas á rejeição. Foi também sugerido pelos autores que, uma vez que o colágeno do tipo $V$ é uma molécula altamente conservada entre indivíduos e espécies, este é alvo na resposta de rejeição no pulmão funcionando como um antígeno.

A utilização de modelos experimentais em animais para estudar as DDTC é fundamental, tendo em vista seu acometimento progressivo e cujas manifestações clínicas só ocorrem quando a doença já se encontra em estágio avançado. Desta forma, o estudo da fisiopatologia e lenta progressão da doença só é possível através de modelos experimentais em animais.

As manifestações esofágicas nas DDTC são muito freqüentes. Na esclerodermia chega a $90 \%$ a prevalência de envolvimento em alguns levantamentos clínicos ${ }^{2-4}$. Sabe-se que a porção distal e o EEI são os mais acometidos e podem apresentar erosões e ulcerações pépticas na mucosa decorrentes do refluxo gastroesofágico ${ }^{11}$. Este refluxo leva a microaspirações repetitivas de conteúdo gástrico para o trato respiratório, contribuindo para o desenvolvimento de doenças do interstício pulmonar (DIP) ${ }^{18}$. No lúpus eritematoso sistêmico, o acometimento do trato digestivo é discreto, sendo os principais distúrbios relacionados a motilidade ${ }^{14} . \mathrm{Na}$ polidermatomiosite do adulto a incidência é de 10\% a $15 \%$ dos casos, com acometimento da musculatura esofágica superior, além da musculatura da laringe, levando a disfagia e distonia ${ }^{9,29}$. Na artrite reumatóide a principal lesão é da musculatura proximal com distúrbio no peristaltismo ${ }^{7,22}$. Clinicamente, os sintomas gastrointestinais mais referidos pelos pacientes com esclerodermia e doenças relacionadas são disfagia (61\%), pirose (77\%), náusea e vômito (58\%), diarréia (53\%), constipação intestinal (31\%) e incontinência fecal $(13 \%)^{30}$.

Nesta doença, o acometimento esofágico destaca-se principalmente pela fibrose da lâmina própria, submucosa e camada muscular do esôfago, presença de áreas com células inflamatórias, causando diminuição do peristaltismo e atrofia da musculatura. Estas características estão relacionadas a estágios muito avançados da doença, tendo em vista que a análise morfológica do esôfago de pacientes com esclerodermia só é feita em casos em que o paciente é sintomático, através de biópsia, ou em casos em que o paciente foi submetido a uma esofagectomia; ou tardiamente, após o óbito. Desta forma, a comparação com um modelo experimental em que é estudado o processo evolutivo da doença é dificultada.

Contudo, em nosso estudo, evidenciamos um acúmulo de fibras colágenas na submucosa e camada muscular do esôfago de coelhos imunizados com colágeno V. Quando avaliadas pela imunohistoquímica pudemos evidenciar que na verdade o que está ocorrendo é um remodelamento da matriz extracelular, com aumento de alguns tipos de colágeno e redução de outros. Este remodelamento provavelmente está relacionado a um processo ainda inicial da doença. $A$ ausência de atrofia da camada muscular como ocorre em humanos nos sugere a característica inicial de tal processo, visto que quando avaliamos a espessura e área da camada muscular não encontramos diferença entre os grupos controle e imunizado.

A utilização de modelos experimentais em animais é bastante importante no entendimento do processo evolutivo da esclerodermia. Porém, poucos são os modelos de esclerodermia com manifestações esofágicas. Gershwin, em 1981, descreveu que galinhas da linhagem UCD 200 desenvolviam lesão endotelial espontânea seguida de fibrose e infiltração mononuclear no esôfago em estágios iniciais da doença ${ }^{20}$.

Existem diversos modelos que estudam a esclerodermia. Modelos genéticos como o Tsk1/+, em rato ${ }^{25}$ e da linhagem UCD 200 em galinhas ${ }^{20}$, modelos induzidos por drogas como por bleomicina ${ }^{31}$ e os induzidos por transplante de células como os induzidos por enxerto versus hospedeiro ${ }^{13}$. Diversos são os modelos, contudo nenhum manifesta todas as alterações da esclerodermia. Apesar disto eles continuam sendo fundamentais no entendimento da fisiopatologia da doença. A busca por um modelo que apresente todas as manifestações da esclerodermia é essencial, pois estaríamos mais próximos do real processo que ocorre nos humanos. Em 2004, Ruzek et al. ${ }^{23}$ apresentaram um modelo modificado de esclerodermia induzido por enxerto versus hospedeiro que manifesta os principais aspectos da doença em humanos. No modelo de esclerodermia induzido por colágeno $\mathrm{V}$ em coelhos, Yoshinari et al.$^{32}$ verificaram que diversos órgãos estão acometidos tais como a pele, o coração, o esôfago, os rins, a sinóvia e os pulmões ${ }^{26,27}$, também sugerindo um modelo com acometimento das principais vísceras.

No modelo induzido por colágeno $V$ verificamos que o acometimento esofágico de fato se assemelha ao observado em humanos com esclerose sistêmica, apresentando-se em uma fase inicial para animais sacrificados até 120 dias. O estudo do esôfago em animais sacrificados com tempo superior é essencial para podermos esclarecer melhor o processo fisiopatológico no qual o esôfago está envolvido. 
Julião GPS et al. Alterações esofágicas em modelo de esclerodermia induzido por colágeno.

Julião GPS, Pereira DD, Anjos DM dos, Teodoro WR, Yoshinari NH, Velosa APP. Manifestations in the esophagus in the scleroderma model induced by type $\mathrm{V}$ collagen in rabbits. Rev Med (São Paulo). 2007 jul.-set.;86(3):163-73.

\begin{abstract}
S: Backgrounds: Sclerosis systemic that usually affects the esophagus. However its patologic mechanism is still unknown. Objective: Evaluate the manifestation of the esophagus in a experimental model of scleroderma induced by type $\mathrm{V}$ collagen in rabbits. Matherial and Methods: 39 rabbits submited to the model immunization were morfologicaly analised. Results: A progressive deposit of collagen fibers was observed in H\&E and Tricomico of Masson. Which was confirmed by the imunofluorescence. Conclusion: We concluded that the characteristics observeds are similar to what happens in the esophagus of human, but in an earlier period.
\end{abstract}

KEY WORDS: Scleroderma, localized. Esophageal diseases. Models, animal. Rabbits. Collagen type V. Disease progression.

\title{
REFERÊNCIAS
}

1. Aumailley M, Timpl R. Attachment of cells to basement membrane collagen type IV. J Cell Biol. 1986;103(4):1569-75.

2. Cecil RL, Goldman L, Ausiello DA. Cecil textbook of medicine. 22nd ed. Philadelphia: Saunders; 2004.

3. Cotran RS, Kumar V, Collins T, Robbins SL. Robbins pathologic basis of disease. 6th ed. Philadelphia: Saunders; 1999.

4. Cozzi F, Zucchetta P, Durigon N, Marzola MC, Bullo A, Favaro $M$, et al. Changes in esophageal peristalsis in diverse clinical forms and antibody specificity in scleroderma: a scintigraphic study in 100 cases. Reumatismo. 2003;55(2):86-92.

5. Cremer MA, Rosloniec EF, Kang AH. The cartilage collagens: a review of their structure, organization, and role in the pathogenesis of experimental arthritis in animals and in human rheumatic disease. $\mathrm{J} \mathrm{Mol} \mathrm{Med.}$ 1998;76(3-4):275-88.

6. Fujii K, Fujimoto W, Ueda M, Makino E, Arata J. Detection of anti-type VII collagen antibody in Sjogren's syndrome/lupus erythematosus overlap syndrome with transient bullous systemic lupus erythematosus. $\mathrm{Br} \mathrm{J}$ Dermatol. 1998;139(2):302-6.

7. Geterud A, Bake B, Bjelle A, Jonsson R, Sandberg N, Ejnell $\mathrm{H}$. Swallowing problems in rheumatoid arthritis. Acta Otolaryngol. 1991;111(6):1153-61.

8. Haque MA, Mizobuchi T, Yasufuku K, Fujisawa $T$, Brutkiewicz RR, Zheng $Y$, et al. Evidence for immune responses to a self-antigen in lung transplantation: role of type $V$ collagen-specific $T$ cells in the pathogenesis of lung allograft rejection. J Immunol. 2002;169(3):1542-9.

9. Joshita Y, Yoshida Y, Kimura K, Yoshida M. Manometrical study of the pharynx and the pharyngoesophageal sphincter in patients with polymyositis. Nippon Shokakibyo Gakkai Zasshi. 1991;88(3):651-8.

10. Kemp JD, Madri JA. The immune response to human type III and type V (AB2) collagen: antigenic determinants and genetic control in mice. Eur $\mathrm{J} \mathrm{Immunol.}$
1981 Feb;11(2):90-4.

11. Klippel JH, Dieppe P. Rheumatology. St. Louis: Mosby; 1994.

12. Kuhn KA, Kulik L, Tomooka B, Braschler KJ, Arend WP, Robinson WH, et al. Antibodies against citrullinated proteins enhance tissue injury in experimental autoimmune arthritis. J Clin Invest. 2006;116(4):961-73.

13. Lakos G, Takagawa S, Varga J. Animal models of scleroderma. Methods Mol Med. 2004;102:377-93.

14. Lapadula G, Muolo P, Semeraro F, Covelli M, Brindicci $D$, Cuccorese $G$, et al. Esophageal motility disorders in the rheumatic diseases: a review of 150 patients. Clin Exp Rheumatol. 1994;12(5):515-21.

15. Linsenmayer TF, Fitch JM, Birk DE. Heterotypic collagen fibrils and stabilizing collagens. Controlling elements in corneal morphogenesis? Ann N Y Acad Sci. 1990;580:143-60.

16. Mackel AM, DeLustro F, Harper FE, LeRoy EC. Antibodies to collagen in scleroderma. Arthritis Rheum. 1982;25(5):522-31.

17. Mares DC, Heidler KM, Smith GN, Cummings OW, Harris ER, Foresman $B$, et al. Type $V$ collagen modulates alloantigen-induced pathology and immunology in the lung. Am J Respir Cell Mol Biol. 2000;23(1):62-70.

18. Marie I, Dominique S, Levesque H, Ducrotte $P$, Denis $\mathrm{P}$, Hellot MF, Courtois $\mathrm{H}$. Esophageal involvement and pulmonary manifestations in systemic sclerosis. Arthritis Rheum. 2001;45(4):346-54.

19. Moreland LW, Gay RE, Gay S. Collagen autoantibodies in patients with vasculitis and systemic lupus erythematosus. Clin Immunol Immunopathol. 1991;60(3):412-8.

20. Nguyen VA, Sgonc R, Dietrich H, Wick G. Endothelial injury in internal organs of University of California at Davis line 200 (UCD 200) chickens, an animal model for systemic sclerosis (Scleroderma). J Autoimmun. 2000;14(2):143-9.

21. Niyibizi C, Fietzek PP, van der Rest M. Human placenta type $\mathrm{V}$ collagens. Evidence for the existence of an alpha 
$1(\mathrm{~V})$ alpha 2(V) alpha 3(V) collagen molecule. J Biol Chem. 1984;259(22):14170-4.

22. Peretz A, Muller G, Praet JP, Ham H, Famaey JP. Oesophageal involvement in rheumatoid arthritis patients: a study with oesophageal radionuclide transit using 81Krm. Nucl Med Commun. 1991;12(10):901-6.

23. Ruzek MC, Jha S, Ledbetter S, Richards SM, Garman RD. A modified model of graft-versus-host-induced systemic sclerosis (scleroderma) exhibits all major aspects of the human disease. Arthritis Rheum. 2004;50(4):1319-31.

24. Sackner MA, Heinz ER, Steinberg AJ. The heart in scleroderma. Am J Cardiol. 1966;17(4):542-59.

25. Siracusa LD, McGrath R, Ma Q, Moskow JJ, Manne $\mathrm{J}$, Christner PJ, et al. A tandem duplication within the fibrillin 1 gene is associated with the mouse tight skin mutation. Genome Res. 1996;6(4):300-13.

26. Teodoro WR. Imunogenicidade ao colágeno do tipo $V$ em coelhos. Um novo modelo experimental para o estudo da patogênese da vasculite de hipersensibilidade autoimune. São Paulo: Faculdade de Medicina, Universidade de São Paulo; 2001.

27. Teodoro WR, Velosa AP, Witzel SS, Garippo AL, Farhat C, Parra ER, Sonohara S, Capelozzi VL, Yoshinari NH. Architectural remodelling in lungs of rabbits induced by type $\mathrm{V}$ collagen immunization: a preliminary morphologic model to study diffuse connective tissue diseases. Pathol Res Pract. 2004;200(10):681-91.

28. Towbin H, Staehelin T, Gordon J. Electrophoretic transfer of proteins from polyacrylamide gels to nitrocellulose sheets: procedure and some applications. Proc Natl Acad Sci USA. 1979;76(9):4350-4

29. Wang SJ, Lin WY, Hsu CY, Kao CH, Chang CP, Lan JL. Solid phase radionuclide esophageal motility in polymyositis and dermatomyositis. Gaoxiong Yi Xue Ke Xue Za Zhi. 1993;9(6):338-42.

30. Weston S, Thumshirn M, Wiste J, Camilleri M. Clinical and upper gastrointestinal motility features in systemic sclerosis and related disorders. Am J Gastroenterol. 1998;93(7):1085-9.

31. Yamamoto T, Takagawa S, Katayama I, Yamazaki $\mathrm{K}$, Hamazaki $\mathrm{Y}$, Shinkai $\mathrm{H}$, et al. Animal model of sclerotic skin. I: Local injections of bleomycin induce sclerotic skin mimicking scleroderma. J Invest Dermatol. 1999;112(4):456-62.

32. Yoshinari NH, Teodoro WR, Ogido LTI, Velosa APP, Prizon CP, Miron B, Bissoli JCC, Cuentas ERP, Capelozzi VL. Modelo experimental de doenças difusas do tecido conjuntivo (DDTC) induzido por colágeno do tipo V. Rev Bras Reumatol. 2002;42:295-305. 